\title{
EFFECT OF LEAD ON STRUCTURAL CHANGES IN LIVER OF WISTAR RATS UNDER THE CONDITIONS OF ACUTE EXPERIMENT
}

\section{Oleg Zayko ${ }^{1 凶} \mathbb{( D}$, Vadim Astashov ${ }^{1} \mathbb{D}$, Anna Sindireva ${ }^{2} \mathbb{D}^{\mathbb{D}}$, Karina Basnakyan ${ }^{1} \mathbb{D}^{\mathrm{D}}$, Arina Lukyanchikova}

\author{
${ }^{1}$ RUDN University, Moscow, Russia \\ ${ }^{2}$ Tyumen State University, Tyumen, Russia
}

\section{oleg.zayko@bk.ru}

ABSTRACT - The purpose of this study was to evaluate the structural transformations of Wistar rats liver after oral administration of lead salts. Under the conditions of acute experiment during 5 days the Wistar rats were orally administered the lead acetate solution in the amount of 3 $\mathrm{mg} / \mathrm{kg}$. Histological studies were carried out at OSMU upon the completion of the experiment. Effect of toxic doses of lead causes symptoms of both steatosis and hydropic degeneration of the liver. It is assumed that the appearance of hepatic steatosis reflects the reaction of hepatocytes to hemic hypoxia caused by the action of lead, while the signs of hydropic degeneration expressed in varying degrees reflect its direct toxic effect.

KEY W ORDS — lead, liver, hepatocytes, hydropic degeneration, hepatic steatosis.

\section{RELEVANCE}

In recent decades, heavy metals are increasingly frequently named as the most dangerous environmental pollutants. Their migration and redistribution in the components of ecosystems depend both on the whole complex of natural factors, and the intensity and nature of technogenesis. Lead is not a vital element. It is toxic and belongs to danger class I. Its inorganic compounds interfere with the metabolism and are the enzymes inhibitors (like most of the heavy metals). One of the most insidious consequences of the action of inorganic lead compounds is its ability to accumulate in a number of organs, including the liver, and to be a constant source of poisoning for a long time. The main source from which lead enters the body, is the food, and also the inhaled air plays the important role. Absorption in the gastrointestinal tract is up to a $5-10 \%$ in adults, and $50 \%$ in children. Thus, there is a need to assess the toxic effect of lead.
Received 22 March 2021;

Received in revised form 1 May 2021; Accepted 5 May 2021

The purpose of this study: to evaluate the structural transformations in the liver of Wistar rats after oral administration of lead salts.

\section{METHODS}

20 male Wistar rats aged 4-5 months, weighing 200-220 g were divided into an experimental and control group - 10 rats in each group. The rats were maintained in standard cages under regular daily alternation of light and darkness, temperature $20-22^{\circ} \mathrm{C}$ and free access to water and food. The studies were carried out in in compliance with the CIOMS-ICLAS International Guiding Principles for Biomedical Research Involving Animals.

Under the conditions of acute experiment during 5 days the Wistar rats were orally administered the lead acetate solution in the amount of $3 \mathrm{mg} / \mathrm{kg}$. Histological studies were carried out at OSMU upon the completion of the experiment. The cut and oriented liver acinuses were fixed in $10 \%$ neutral buffered formalin $(\mathrm{pH}=7.2-7.4)$. They were dehydrated and embedded in paraffin according to conventional technique. 4-5 microns thick paraffin sections were stained with hematoxylin and eosin. Ziehl-Neelsen method (detection of fuchsinophile acid resistant intranuclear inclusions) by Lily's formulation (1969) was used to identify lead pellets in a complex with protein deposits in the form of intranuclear inclusions in the cells of renal tubule. Sections were stained with carbol fuchsin (dissolve $25 \mathrm{~g}$ of phenol in $50 \mathrm{ml}$ alcohol, then in $5 \mathrm{~g}$ of basic fuchsin, fill with distilled water to $500 \mathrm{ml}$ ) over a fire until the vapor (4-5 minutes), then the glass was cooled down and colorant drained. Rinsing was performed in running water with differentiation in a $5 \%$ solution of sulfuric acid, followed by counterstaining with methylene blue. Pearls reaction was used to identify hemosiderin.

\section{RESULTS}

The following data were obtained after the analysis of liver micropreparations of the experimental animals. During an acute experiment in lead poisoning conditions, the signs of hydropic degeneration in the hepatic tissue were observed from the very first day of the experiment. Predominant changes were observed in centrolobular localization hepatocytes, while 
proteinosis, recognizable in the light microscope by the irregular cytoplasm (crumpled up paper symptom) was represented unevenly, in the form of peculiar nests. Plethora of central veins and expansion of adjacent sinusoids were observed, and the said changes were already significantly expressed at day 3 or more of the experiment (fig. 1).

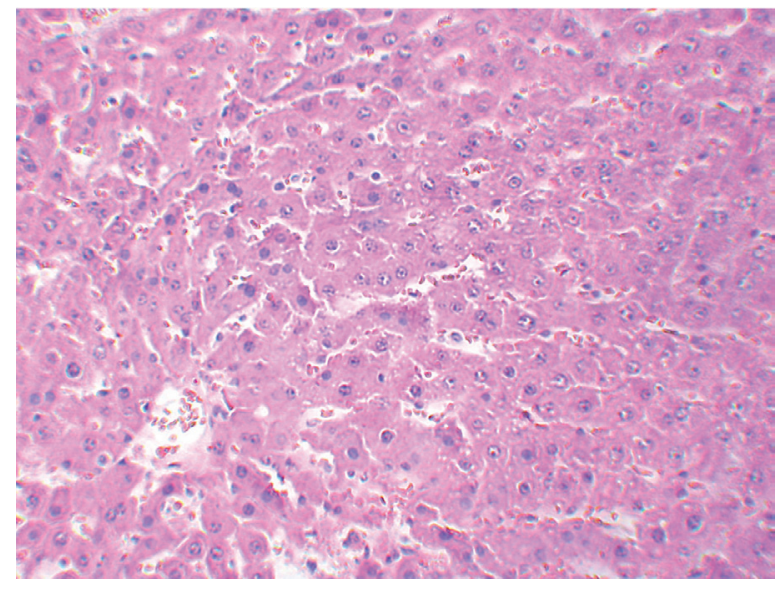

Fig. 1. Lead poisoning. Dilatation and congestion of central segments of sinusoids. Haematoxylin and eosin staining. $\times 270$

Signs of proteinosis were characterized by a greater area of distribution covering even the peripheral parts of the acinus. The dystrophy in some hepatocytes of centrolobular localization was expressed up to a balloon type, with the cells with signs of colliquative necrosis (fig. 2).

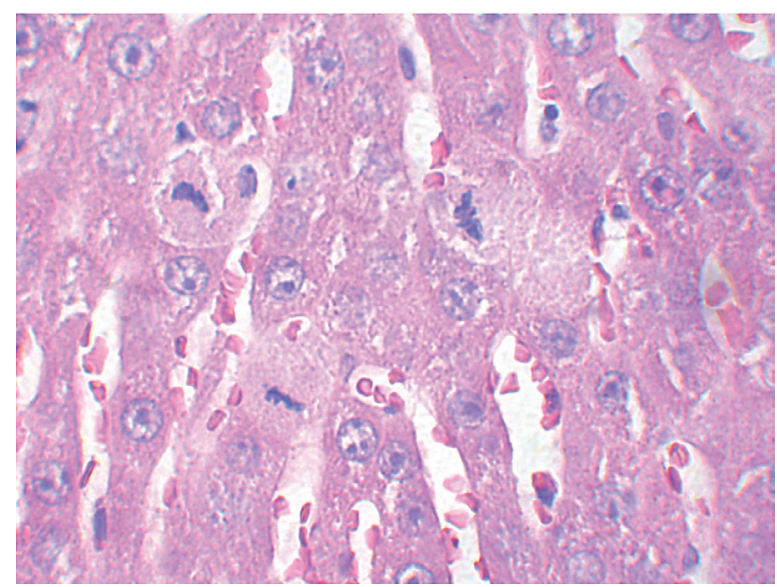

Fig. 2. Acute lead poisoning. Dilatation and congestion of sinusoids. Coagulative necrosis of hepatocytes, mitoses. Haematoxylin and eosin staining. $\times 900$
The lumen of the sinusoids and perisinusoidal space was marked with the appearance of hepatic macrophages - Kupffer cells as a rule arranged in groups up to 5-8 cells (fig. 3).

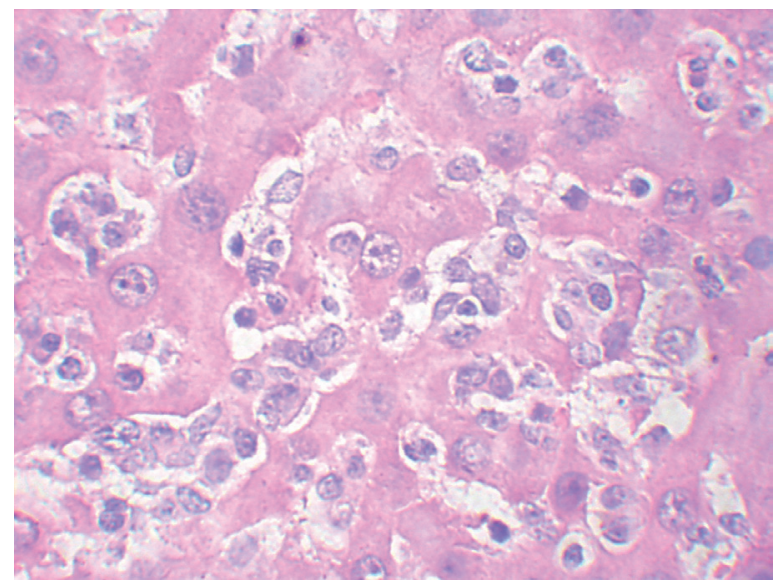

Fig. 3. Hepatic tissue amid acute experiment of lead poisoning. Clustering of Kupffer cells in congested dilated sinusoids, regenerative transformation of hepatocytes. Haematoxylin and eosin staining. $\times 900$

By the end of the experiment the majority of the formulations had the signs of not only proteinosis, but also steatosis with small-drop character and represented diffusely in liver acinus (fig. 4).

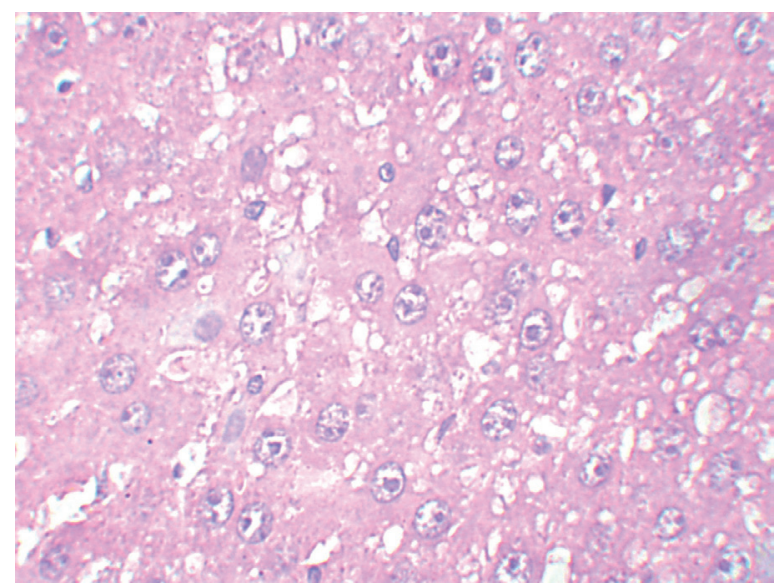

Fig.4. Lead poisoning. Disseminated small-droplet fatty degeneration of hepatocytes. Coagulative necrosis of certain cells. Haematoxylin and eosin staining. $\times 900$

Hepatocytes with regenerative changes, hyperchronia of cores with increased size, appearance of binuclear hepatocytes were also observed, mitosis was rarely observed. 


\section{CONCLUSION}

The effect of toxic doses of lead results in symptoms of both hepatic steatosis and hydropic degeneration of the liver. It is assumed that the appearance of steatosis reflects the reaction of hepatocytes to hemic hypoxia caused by the action of lead, while the signs of hydropic degeneration is expressed in varying degrees reflect its direct toxic effect.

\section{REFERENCES}

1. Stuart J Forbes, Philip N Newsome «Liver regeneration - mechanisms and models to clinical application» // Natural Reviews. Gastroenterology \& Hepatology. - 2016 Aug;13. - №8. - p.473-485 DOI: 10.1038 / nrgastro.2016.97.

2. Jorge Vizuete, Marcos Pérez-López, María Prado Míguez-Santiyán, David HernándezMoreno «Mercury (Hg), Lead (Pb), Cadmium (Cd),
Selenium (Se), and Arsenic (As) in Liver, Kidney, and Feathers of Gulls: A Review» // Reviews Environmental contamination and toxicology. - 2019. P. 85-146 DOI: $10.1007 / 398 \_2018 \_16$.

3. Alan N Hunt, Anagha Malur, Tual Monfort, Pavlos Lagoudakis, Sumeet Mahajan, Anthony D Postle, Mary Jane Thomassen «Hepatic Steatosis Accompanies Pulmonary Alveolar Proteinosis» // American journal of Respiratory Cell and Molecular Biology. - 2017. - №4. - p.448-458 DOI:10.1165/rcmb.2016-0242OC.

4. Ju-Wook Lee, Hoon ChoI, Un-Ki Hwang, Ju-Chan Kang, Yue JaI Kang, Kwang IL Kim, Jun-Hwan KIm «Toxic effects of lead exposure on bioaccumulation, oxidative stress, neurotoxicity, and immune responses in fish: A review» // Environmental Toxicology and Pharmacology. - 2019. p. 101-108 DOI: 10.1016/j.etap.2019.03.010 